\title{
Voltage Quality Improvement Using Solar Photovoltaic System
}

\author{
Denisa Galzina \\ Measurement department, HOPS, Zagreb, Croatia \\ e-mail: denisa.galzina@hops.hr
}

Cite as: Galzina, D., Voltage Quality Improvement Using Solar Photovoltaic System, J. sustain. dev. energy water environ. syst., 3(2), pp 140-150, 2015, DOI: http://dx.doi.org/10.13044/j.sdewes.2015.03.0011

\begin{abstract}
Solar power and wind are the most promising distributed energy sources. The photovoltaic system has attracted significant attention in recent years. Although their benefits are numerous, they are known to create power quality issues, because of the power electronic converters they use. This paper investigates if there is a possibility to improve power quality only by connecting a solar photovoltaic system to the grid, and then gives results of on-site power quality measurements in the grid before and after the connection of the solar photovoltaic system.
\end{abstract}

\section{KEYWORDS}

Voltage quality, Photovoltaic system, Voltage harmonics, Voltage unbalance, Active power filter, Inverter.

\section{INTRODUCTION}

Over the years, photovoltaic systems have become more and more appealing. The reason for that is the fact that photovoltaic cells convert solar energy directly to electric energy. They do not have rotating parts, there is no noise and low maintenance, and they require less time to install and start up a new unit for generation. Also, solar energy is abundantly available on earth, is a non-polluting energy source and available continually free of cost.

With the increase of renewable energy propagation to the grid, the power quality of the medium and low voltage distribution system is becoming a major area of interest [1, 4]. A majority of the renewable energy systems integration to the grid takes place with the aid of power electronic converters. The main purpose of power electronic converters is integration of distributed generation to the grid in compliance with power quality standards [5].

The Photovoltaic (PV) array and the battery are connected to the AC grid via a common DC/AC inverter. AC output voltage is created by switching the full bridge in an appropriate sequence. The inverter topologies can be divided into two types, which are single-stage and multi-stage inverters. The single stage inverter has many advantages such as low cost, high efficiency, robust performance, high reliability and simple structure.

On the other hand, the multi stage inverters accept a wide range of input voltage variations, but have high price, low efficiency, complicated structure and isolated topologies. Nevertheless, with high frequency transformers, they can extract power from the source even when the DC voltage is very low.

However, high frequency switching of inverters can inject additional harmonics to the systems, creating major voltage quality issues if not implemented properly [6]. 
Therefore, the inverters had to be modified in order to provide the reactive power compensation and harmonic suppression of the sole PV system. The modification was done so successfully, that PV inverters nowadays are able to improve the voltage quality parameters at the Point of Common Coupling (PCC) [7].

In the Croatian distribution system there is a growing request for integration of renewable energy sources into the grid, mostly wind power, but also PV systems. In order to fulfil all requirements from Grid code, the user is obliged to measure the impact of renewable energy source to the voltage quality parameters of the grid. Measurement consists of two parts, 7-day voltage quality measurement prior to connection of the source, and 7-day measurement after the source is connected. Both have to be performed with Class A instrument, in compliance with EN 50160 standard.

The measurements described in the paper, are made on multiple 10 to $30 \mathrm{~kW} \mathrm{PV}$ system connected to low voltage distribution grid.

\section{POWER QUALITY ISSUES}

The ability of the electric system to deliver electric power without interruption is termed $100 \%$ reliability. The ability to deliver a clean signal without variations in the nominal voltage or current characteristics is termed high power quality. Higher or lower (than normal) voltage or current can damage or shut down certain types of electrical equipment. Such variations in the normal signal occur on the typical power delivery circuit multiple times per year [8].

A grid-connected PV power system consists of arrays of solar modules, and a DC/AC power inverter, as shown in Figure 1.

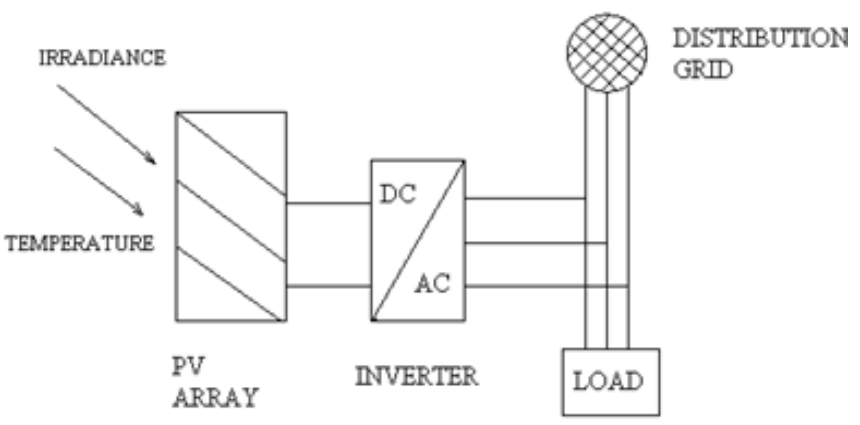

Figure 1. Basic structure of PV power system

Though the output of photovoltaic panel depends on the solar intensity and cloud cover, it is not the only reason for power quality issues. The power quality problems depend on irradiation, but also are based on the overall performance of solar photovoltaic system, including photovoltaic modules, inverter, filters, etc. Studies presented in [9] show that the short fluctuation of irradiance and cloud cover play an important role for distribution grids with high penetration of photovoltaic systems. It suggests that voltage and power mitigation can be achieved by super-capacitors, resulting in an increase of about $20 \%$ in the cost of photovoltaic system.

Voltage harmonics are virtually always present on the utility grid. Nonlinear loads, power electronic loads, and rectifiers and inverters in motor drives are some sources of harmonics. The effects of the harmonics include overheating and equipment failure, faulty operation of protective devices, nuisance tripping of sensitive load and interference with communication circuits. Power electronic equipment creates current distortion that can impact neighbouring equipment. Distributed generation, like photovoltaic or fuel 
cells, are likely to introduce harmonics problem in the system. Harmonics from distributed generation come from inverters and some synchronous machines. The Pulse Width Modulation (PWM) switching inverters produce a much lower harmonic current content than the earlier line-commutated, thyristor-based inverters [10]. One new distortion problem that arises with the modern inverters is that the switching frequencies will occasionally excite resonances in the primary distribution system. This creates non-harmonic frequency signals typically at the $35^{\text {th }}$ harmonic and higher, impacting clocks and other circuitry that depends on a clean voltage zero crossing. A typical situation in which this might occur is an industrial park fed by its own substation and containing a few thousand feet of cable. A quick fix is to add more capacitance in the form of power factor correction capacitors, being careful not to cause additional harmful resonances [11].

\section{IMPROVING POWER QUALITY}

There are technical ways to improve power quality in the distribution grid (such as static var compensators for example), but photovoltaic system manufacturers are trying to eliminate the disturbance before it comes to the grid $[12,14]$. Therefore, filters with their controllers and voltage source converters are embedded in the photovoltaic system, making it safe to connect to the grid.

\section{Filters}

Active power filters are power electronic devices that cancel out unwanted harmonic currents by injecting a compensation current which cancels harmonics in the line current. Shunt active power filters compensate load current harmonics by injecting equal-but opposite harmonic compensating current. Generally, four-wire active power filters have been conceived using four-leg converters [15]. This topology has proved better controllability than the classical three-leg four-wire. The topology of the investigated active power filter and its interconnection with the grid is presented in Figure 2. It consists of a three-leg four-wire voltage source inverter. In this type of applications, the voltage source inverter operates as a current controlled voltage source. The voltage source inverter is a key element of a photovoltaic system as it interfaces with the renewable energy source to the grid and delivers the generated power. The PV system is connected to grid with an inverter coupled to a dc-link. The dc-capacitor decouples the PV system from the grid and also allows independent control of converters on either side of the dc-link. The controller (or conditioner) is the device designed to extract maximum power of PV system and to compensate non-linear and unbalanced loads of the grid, mostly using neuro-fuzzy control [16].

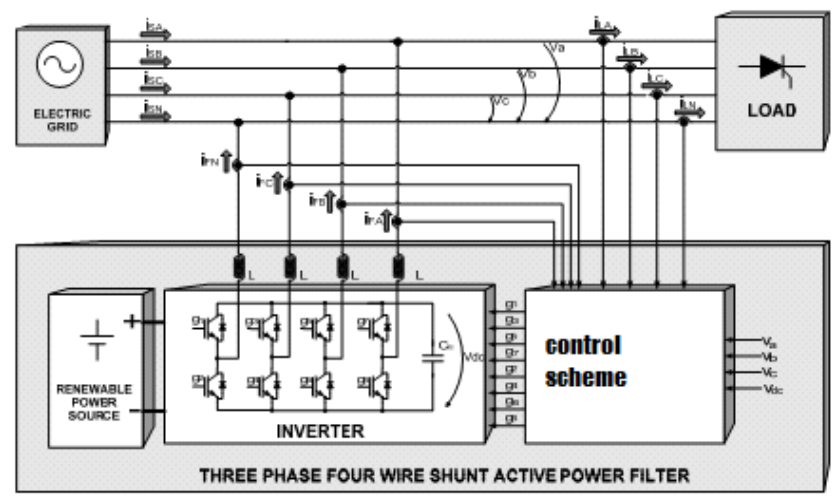

Figure 2. Topology of the active power system 


\section{Voltage source converters}

The other type of power quality mitigation is a Voltage Source Converter (VSC), a power electronic device connected in shunt or parallel to the system, shown in the Figure 3.

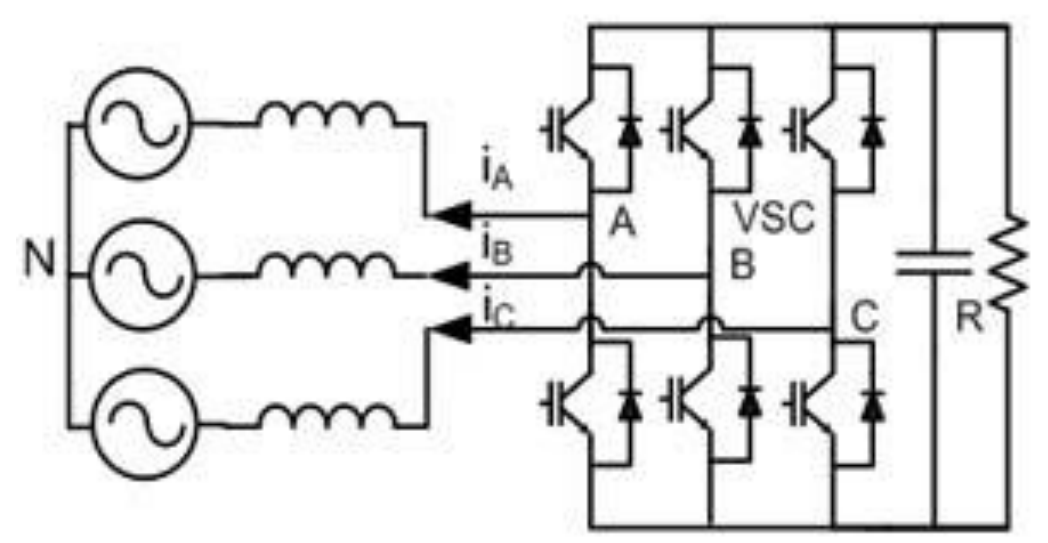

Figure 3. Voltage source converter

It can generate a sinusoidal voltage with any required magnitude, frequency and phase angle. It also converts the DC voltage across storage devices into a set of three phase AC output voltages, and is capable to generate or absorb reactive power. If the output voltage of the VSC is greater than AC bus terminal voltages, it is said to be in capacitive mode. So, it will compensate the reactive power through AC system. The type of power switch used is an IGBT in anti-parallel mode with a diode [17].

\section{THE MEASUREMENT RESULTS}

The Croatian grid code [18] is a technical specification which defines the parameters that network users have to meet in order to ensure safe, secure and economic functioning of the electric system. Therefore, anyone trying to connect to a distribution network has to fulfil minimal technical requirements considering (among others) frequency and voltage deviation, voltage waveform and unbalance, all parameters of voltage quality. In power quality regulations, the Grid code is consistent with EN 50160 standard.

Summary of EN 50160 standard for high voltage is given in Table 1.

Table 1. Summary of EN50160 standard for high voltage

\begin{tabular}{cc}
\hline Voltage disturbance & $\begin{array}{c}\text { Voltage quality index (limit) } \\
\begin{array}{c}\text { Supply voltage } \\
\text { variations }\end{array}\end{array}$ \\
\hline Flicker & $\begin{array}{c}99 \% \text { of the } 10 \text { minute mean r.m.s values for 1 week }( \pm 10 \% \text { of } \\
\text { nominal voltage })\end{array}$ \\
\hline Voltage dip & duration $<1 \mathrm{~s}$, depth $<60 \%$ \\
\hline Unbalance & $\begin{array}{c}95 \% \text { of the } 10 \text { minute mean r.m.s values of the negative phase } \\
\text { sequence component divided by the values of the positive } \\
\text { sequence component for 1 week }(0 \%-2 \%) .\end{array}$ \\
\hline Harmonic voltage & $\begin{array}{r}95 \% \text { of the } 10 \text { minute mean r.m.s values for 1 week lower than } \\
\text { limits provided by means of a table }\end{array}$ \\
\hline
\end{tabular}


One of the most difficult problems that must be dealt with is voltage unbalance. It is a condition in which the three-phase voltages in the system differ by an amount (amplitude), or if the angle between each two phases is not $120^{\circ}$. A measure of the unbalance of the voltage is defined as the ratio of the inverse and direct component, as shown in Figure 4.

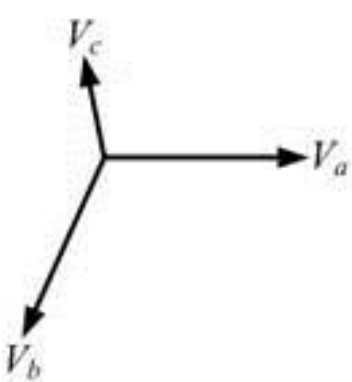

(a)

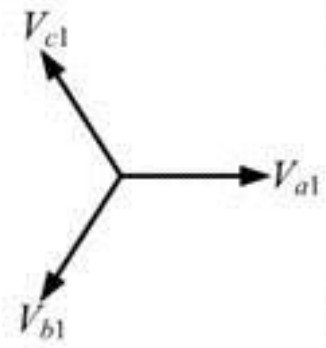

(b)

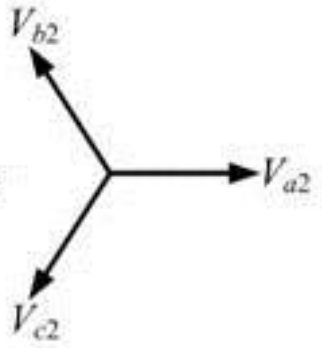

(c)

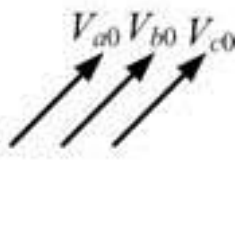

(d)

Figure 4. 1 representation of an unbalanced network (a); its positive sequence (b); negative sequence (c); and zero sequence (d)

Positive, negative, and zero sequence are defined as:

$$
\begin{gathered}
V_{1}=\frac{1}{3}\left(V_{a}+a V_{b}+a^{2} V_{c}\right) \\
V_{2}=\frac{1}{3}\left(V_{a}+a^{2} V_{b}+a V_{c}\right) \\
V_{0}=\frac{1}{3}\left(V_{a}+V_{b}+V_{c}\right)
\end{gathered}
$$

where:

$$
\begin{gathered}
a=e^{j \frac{2 \pi}{3}}=\cos \frac{2 \pi}{3}+j \sin \frac{2 \pi}{3}=-0.5+j 0.866 \\
a^{2}=-0.5-j 0.866
\end{gathered}
$$

Based on positive and negative sequences, the voltage unbalance factor is defined as:

$$
v_{2}[\%]=\frac{V_{2}}{V_{1}} \times 100
$$

The greatest effect of voltage unbalance is on three-phase induction motors. Three phase induction motors are one of the most common loads on the network and are found in large numbers especially in industrial environments. When a three-phase induction motor is supplied by an unbalanced system the resulting line currents show a degree of unbalance that is several times the voltage unbalance. This can be explained with reference to the two contra-rotating fields established when the motor is subjected to voltage unbalance. As an example, a voltage unbalance of $5 \%$ would give rise to a very significant $30 \%$ unbalance in the motor line current leading to a reduction in motor 
efficiency while reducing the insulation life caused by overheating. It is worth noting that average expected life of insulation halves for every $10{ }^{\circ} \mathrm{C}$ of temperature increase.

Steady-state voltage unbalance can arise from unequal loading on each phase or from unbalanced faults on the power system, which cause single phase voltage sags. These sags can range from mild to severe depending on the distance to the fault. An unbalance of more than $1 \%$ is harmful. It causes heating in motors requiring them to be derated. For example, with $5 \%$ unbalance, the motor derating factor is 0.76 . Unbalance can also affect sensitive single phase loads because it creates undervoltages on one or more lines [19].

To make sure the grid will be safe and disturbance free after connection of PV system, the distribution company requires extensive PQ measurement, according to EN50160. It has to be done with Class A instrument, and measurements have to last at least one week prior to connection and one week after the connection of PV system to the grid.

The results are from three MV sites, shown as diagrams and statistical data. The measurement was carried over a period of one week before and one week after the PV system was connected to the grid. All PV systems were connected to MV distribution grid, and PV power was in range of 10 to $30 \mathrm{~kW}$. Some of the most interesting results of the measurement are given here.

PV system A is a $10 \mathrm{~kW}$ power system, and Figures 5, 6 and 7 show the change of voltage unbalance and short-term flicker occurrence in the PCC. Flicker diagram, after the connection, has fewer peaks, and their magnitude is smaller. The highest flicker value before the connection was 4 , whereas after the connection of PV system it was 1.8. The same thing happened to the voltage unbalance; there were two peaks of $60 \%$ and $40 \%$ unbalance, and later it fell to maximum of $1.2 \%$.
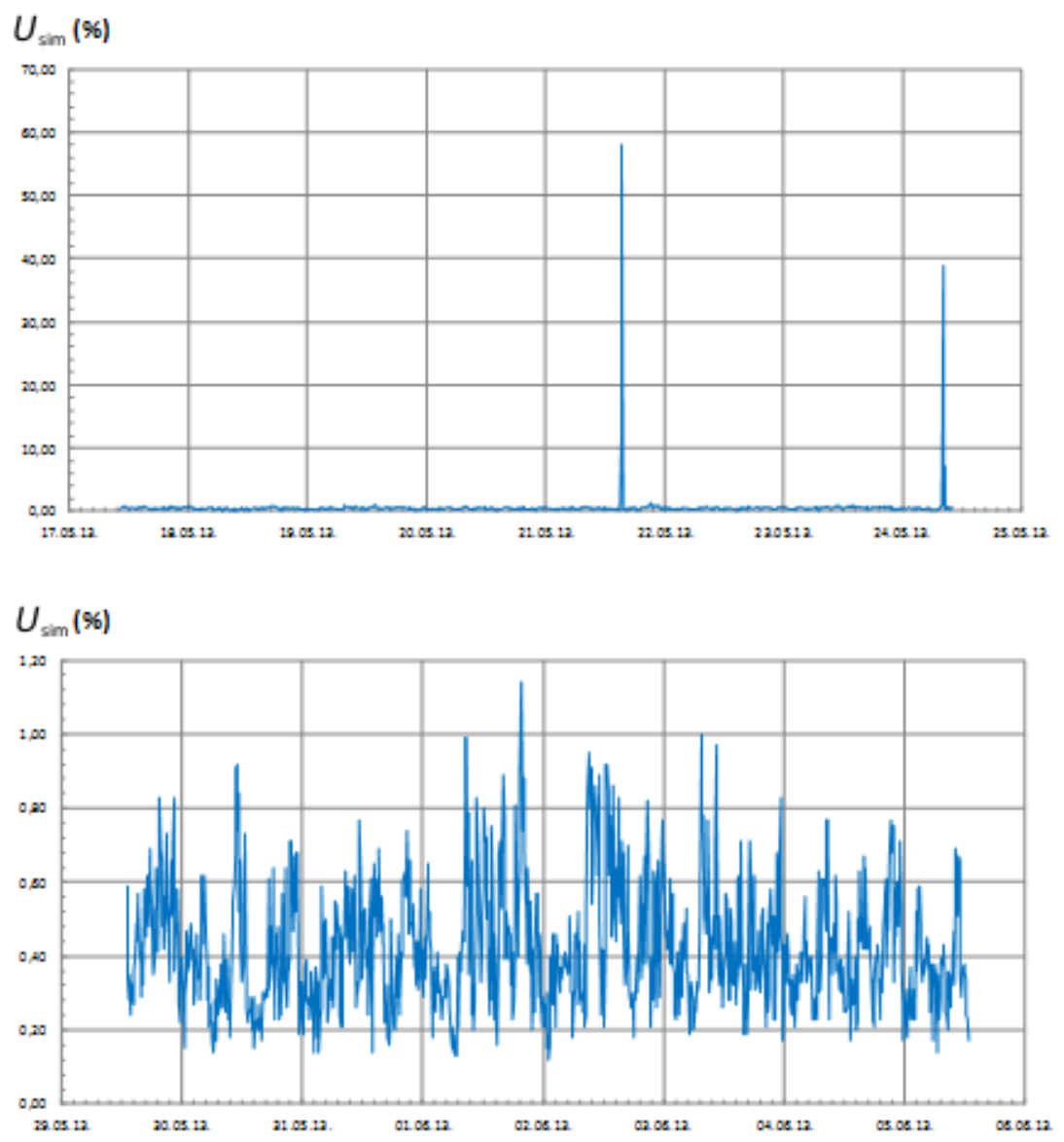

Figure 5. Voltage unbalance $U_{\text {sim }}$ at the PCC before and after the connection of PV system A 


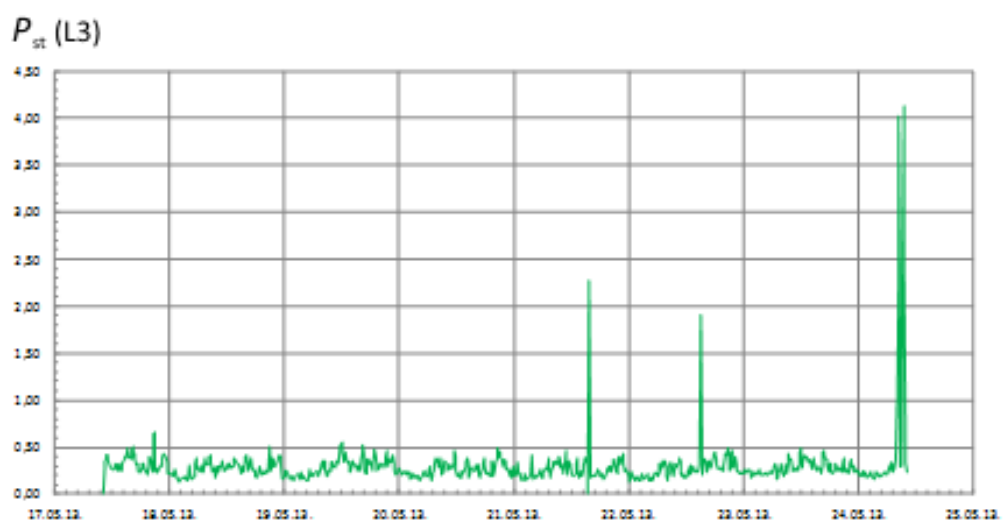

Figure 6. Short term flicker $P_{\text {st }}$ (line L3) before the connection of PV system A

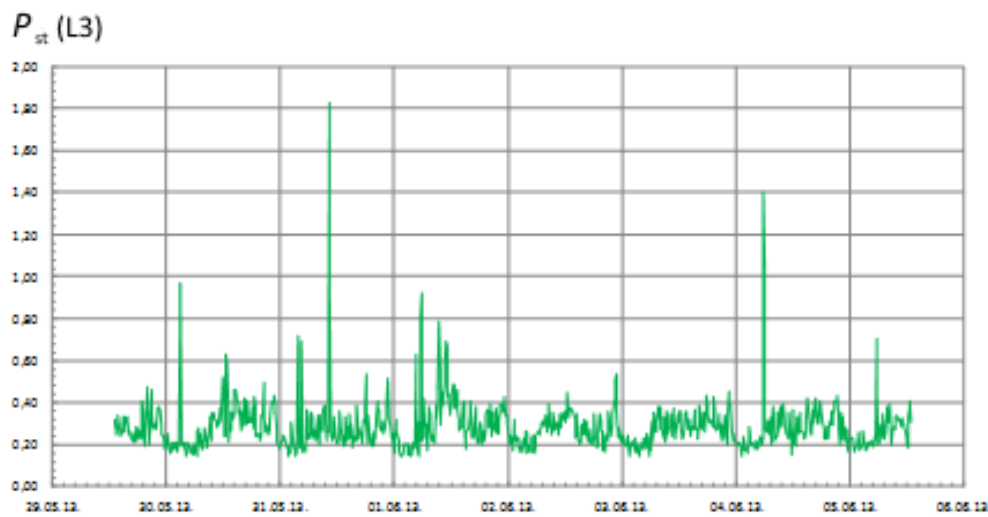

Figure 7. Short term flicker $P_{\text {st }}$ (line L3) after the connection of PV system A

Beside graphical results, the statistical results are also very important. In order to be compliant with EN50160 standard, all parameters have to be within the limits in every $95 \%$ of 7 -week period of observed time. Nevertheless, from a technical point of view it is of great value to know what happens in the remaining $5 \%$ of the time. Table 2 . shows the data before and after the system A was connected to the grid.

Table 2. Statistical data for PV system A

\begin{tabular}{ccccc}
\hline \multirow{2}{*}{ Parameter } & \multicolumn{2}{c}{ Before connection } & \multicolumn{2}{c}{ After connection } \\
\cline { 2 - 5 } & $95 \%$ & $100 \%$ & $95 \%$ & $100 \%$ \\
\hline Usim [\%] & 0.79 & 58.12 & 0.75 & 1.14 \\
$P_{\text {st }}$ & 0.61 & 4.3 & 0.57 & 2.08 \\
\hline
\end{tabular}

Even though the results in $95 \%$ of the time did not change a lot, it can be seen how voltage unbalance in $100 \%$ of the time was almost $60 \%$, and after the connection of the PV system fell to a reasonable $1.14 \%$. The same thing is with short-term flicker and the conditions in the grid are much better after the connection.

PV system B is a $20 \mathrm{~kW}$ power system, and Figures 8,9 and 10 show the change of total harmonic distortion and long-term flicker occurrence in the PCC. The THD diagram, after the connection, is less pointy, and the maximum value has fallen from 8.5 to $7.2 \%$. The maximum value of long-term flicker fell $20 \%$, from 1.2 to 1 . It means that the PV inverter was able to compensate the higher harmonics that already existed in the network before the connection of the PV system. 

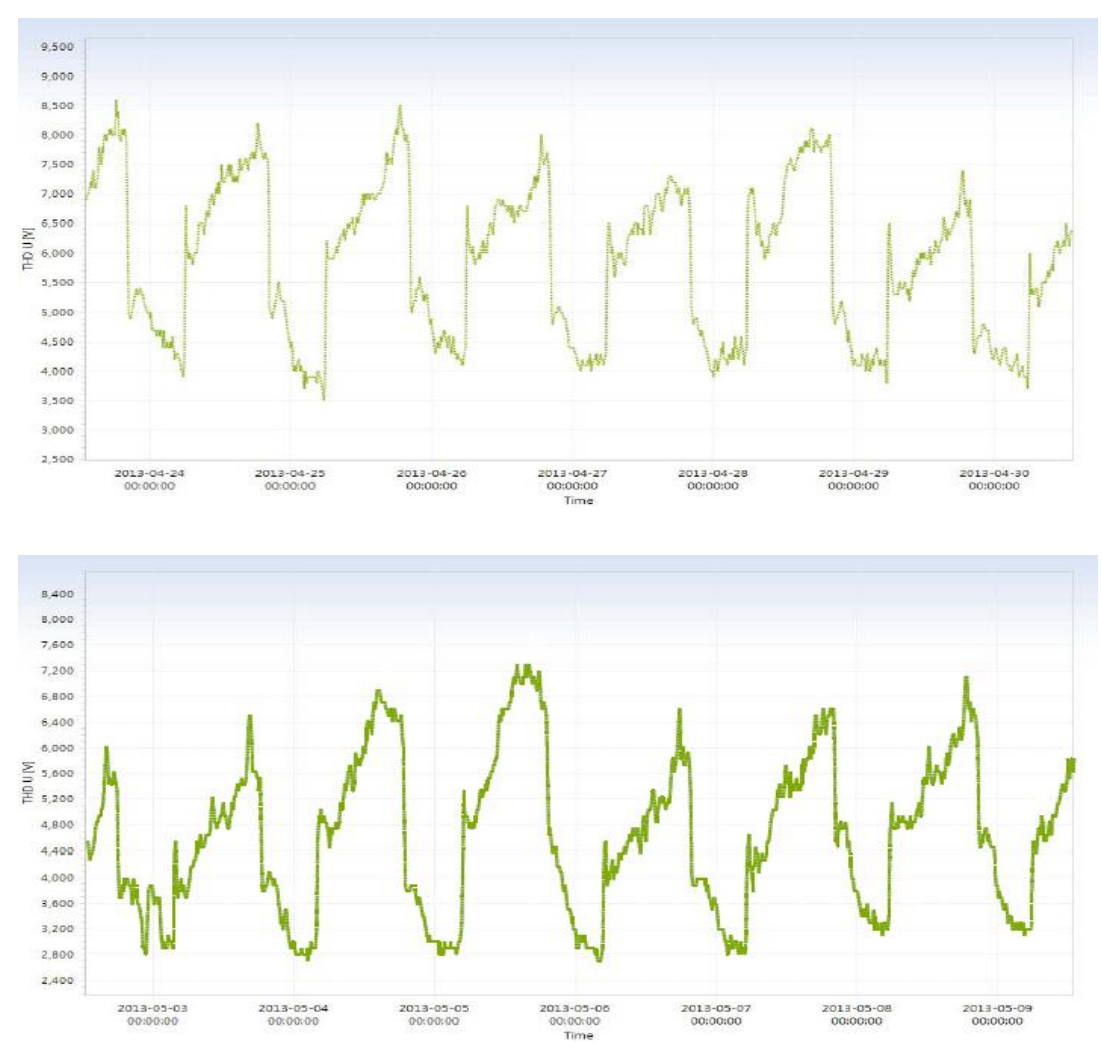

Figure 8. THD (line L3) before and after the connection of PV system B

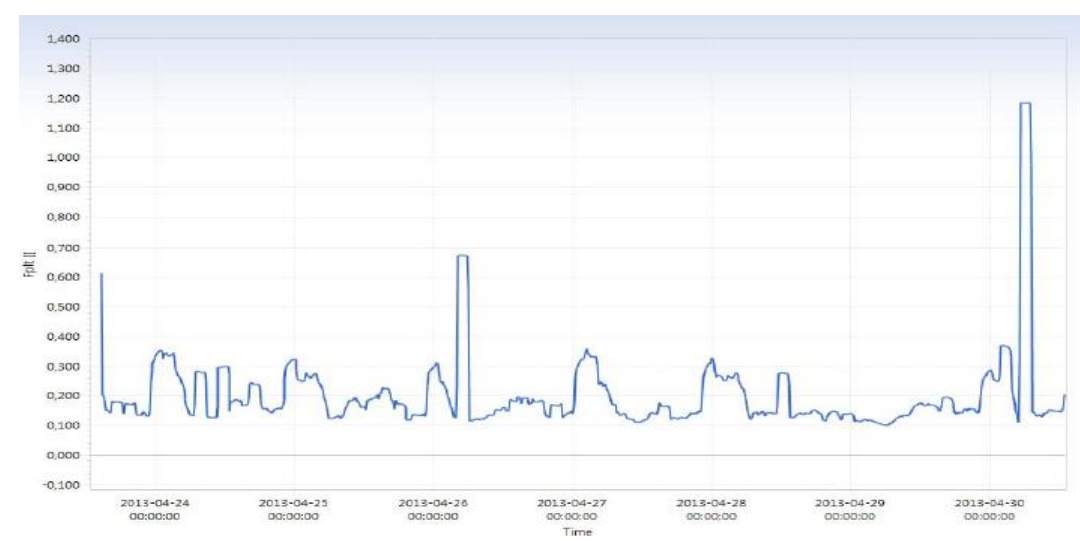

Figure 9. Long term flicker (line L1) before the connection of PV system B

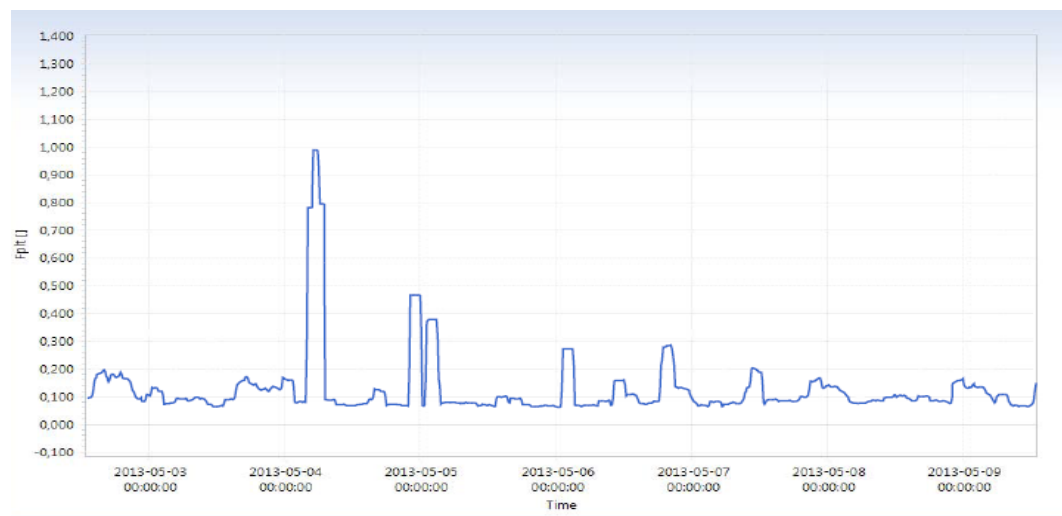

Figure 10. Long term flicker (line L1) after the connection of PV system B 
Statistically, the results are shown in Table 3.

Table 3. Statistical data for PV system B

\begin{tabular}{ccccc}
\hline \multirow{2}{*}{ Parameter } & \multicolumn{2}{c}{ Before connection } & \multicolumn{2}{c}{ After connection } \\
\cline { 2 - 5 } & $95 \%$ & $100 \%$ & $95 \%$ & $100 \%$ \\
\hline THD [\%] & 8.1 & 8.6 & 6.9 & 7.7 \\
$P_{1 \mathrm{t}}$ & 1.18 & 1.88 & 0.45 & 0.99 \\
\hline
\end{tabular}

After the connection, long-term flicker fell on less than $40 \%$ of its initial value for $95 \%$ of the time (from 1.18 to 0.45 ), and for $100 \%$ of the time on $50 \%$ of initial value (from 1.88 to 0.99 ).

PV system $\mathrm{C}$ is a $10 \mathrm{~kW}$ power system, and Figure 11 shows the change of short-term flicker occurrence in the PCC. The maximum value of short-term flicker fell from 7.5 to 3.8 .
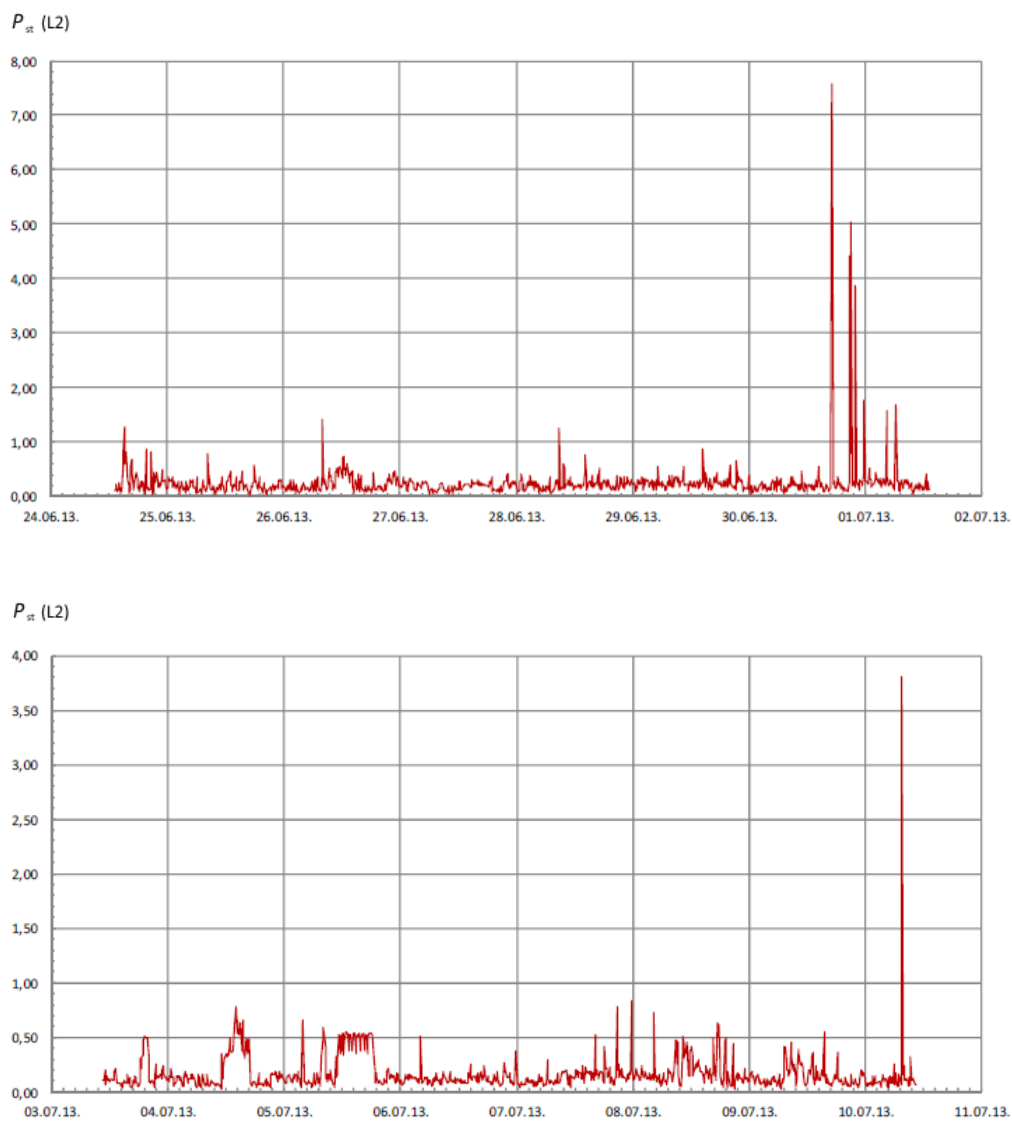

Figure 11. Short term flicker $P_{\text {st }}$ (line L2) before and after the connection of PV system C Statistical results are shown in Table 4.

Table 4. Statistical data for PV system C

\begin{tabular}{ccccc}
\hline \multirow{2}{*}{ Parameter } & \multicolumn{2}{c}{ Before connection } & \multicolumn{2}{c}{ After connection } \\
\cline { 2 - 5 } & $95 \%$ & $100 \%$ & $95 \%$ & $100 \%$ \\
\hline$P_{\text {st }}$ & 0.47 & 7.57 & 0.51 & 3.81 \\
\hline \multicolumn{7}{c}{148} \\
\hline
\end{tabular}


In this case, the occurrence of flicker in $95 \%$ of the time has slightly increased (less than $10 \%$ ) after the connection, but overall occurrence fell to $50 \%$ of its initial value.

\section{CONCLUSION}

The new power-electronic technology plays a very important role in the integration of renewable energy sources into the grid.

PV panels are connected in series and parallel to match the grid voltage, producing DC energy. This DC energy is converted to AC, using inverter. Inverter control feeds active power to the grid using discrete PWM signals, at the same time causing harmonic injection into the grid.

Harmonics cause overheating of electrical distribution system wiring, transformer overheating and shortened transformer service life or false circuit breaker tripping. Electrical fires resulting from distribution system wiring and transformer overheating were rare occurrences until harmonic currents became a problem. Unfortunately, the frequency of such fires is now becoming more common.

Unbalanced currents lead to torque pulsations, increased vibrations and mechanical stresses, increased losses, resulting in lower efficiency and motor overheating, which reduces winding insulation life.

All these problems can cause big financial losses, and should be avoided, whenever possible. The aim of the paper was to show if photovoltaic systems can help with existing power quality problems in network, besides producing "green energy".

So, even though PV systems are said to be the cause of many disturbances, operational results are in contradiction to that hypothesis. Using modern active filters with controllers and voltage source converters, PV systems can produce flawless energy, and even improve the condition of the grid at the point of common coupling by its operation, making solar energy clean, not only ecologically, but also from a technical point of view, as the measurements have confirmed.

\section{REFERENCES}

1. Farhoodnea, M., Mohamed, A., Shareef, H., Zayendehroodi, H., Power Quality Impact of Renewable Energy based Generators and Electric Vehicles on Distribution Systems, ICEEI 2013, Vol. 11, pp 11-17, 2013, http://dx.doi.org/10.1016/j.protcy.2013.12.156

2. Chovatia, C. M., Gupta, N. P, Gupta, P. N., Power Quality Improvement in a PV Panel connected Grid System using Shunt Active Filter, International Journal of Computer Technology and Electronics Engineering, Vol. 2, Issue 4, pp 41-45, 2012.

3. Gupta, A., Garg, P., Grid Integrated Solar Photovoltaic System Using Multi Level Inverter, International Journal of Advanced Research in Electrical, Electronics and Instrumentation Engineering, Vol. 2, Issue 8, pp 3952-3960, 2013.

4. Kadir, A. F. A., Mohamed, A., Shareef, H,. Wanik, M. Z. C., Impact of Multiple Inverter Based Distributed Generation Units on Harmonic Resonance, Renewable Energy \& Power Quality Journal, No. 10, $25^{\text {th }}$ April 2012, No. 280.

5. Khadem, S. K., Basu, M., Conlon, M. F., Power Quality in Grid connected Renewable Energy Systems: Role of Custom Power Devices, International Conference on Renewable Energies and power Quality, Granada Spain, 23-25 March 2010.

6. Aprilia, E. C., Modelling of Photovoltaic (PV) Inverter for Power Quality Studies, Master's Thesis, Technische Universiteit Eindhoven, August 2012. 
7. Prodanovic, M., Green T. C., Control in Power Quality in Inverter-based Distributed Generation, IEEE Industrial Electronics Society, Annual Conference 2002, Vol. 2, pp 1185-1189, http://dx.doi.org/10.1109/IECON.2002.1185441

8. New York State Energy Research and Development Authority, Final report: The Role of Distributed Generation in Power Quality and Reliability.

9. Chicco, G., Schlabbach, J., Spertino, F., Experimental assessment of Waveform Distortion in Grid-connected Photovoltaic Installations, Solar Energy, Vol. 83, pp 1026-1039, 2009, http://dx.doi.org/10.1016/j.solener.2009.01.005

10. EPRI White Paper, Integrating Distributed Resources into Electric Utility Distribution System Technology Review, December 2001.

11. Gyugyi, L., Dynamic Compensation of AC Transmission Line by Solid-State Synchronous Voltage Sources, IEEE Power Engineering Society, Summer Meeting 1993, Vol. 9, No. 2, pp 904-911, 1994, http://dx.doi.org/10.1109/61.296273

12. Kumar, G. G., Kumar, A. A., Renewable Energy Interconnection at Distribution Level to improve Power Quality, International Journal of Engineering and Science, Vol. 2, Issue 5, pp 39-48, 2013.

13. Stetz, T., Yan, W., Braun, M., Voltage Control in Distribution Systems with High Level PV-Penetration - Improving Absorption Capacity for PV Systems by Reactive Power Supply, 25th European PV Solar Energy Con-ference and Exhibition, 6th 10th September 2010, http://dx.doi.org/10.4229/25thEUPVSEC2010-5BV.4.17

14. Akhtar, J., Shamsudheen, P. M., Power Quality Improvement Using Fuzzy Logic Control Static Var Compensator In Power System Network, IOSR Journal of Engineering, Vol. 2, Issue 8, pp 01-08, 2012.

15. Chen, H.-C., Qiu, J.-C., Liu, C.-H., Dynamic Modeling and Simulation of Renewable Energy Based Hybrid Power Systems DRPT 2008, pp 2803-2809, http://dx.doi.org/10.1109/DRPT.2008.4523887

16. Vazquez, J. R., Martin, A. D., Herrera, R. S., Neuro-fuzzy Control of a Grid-connected Photovoltaic System with Power Quality Improvement, EuroCon 2013, Zagreb, Croatia, pp 850-856, 1-4 July 2013, http://dx.doi.org/10.1109/EUROCON.2013.6625082

17. Archana, M., Kondaiah, Y. C. V., Grid Interfacing Inverter of Renewable Energy Sources to Improve the Power Quality in Distribution System, International Journal of Advanced Research in Electrical, Electronics and Instrumentation Engineering Vol. 1, Issue 5, pp 411-418, 2012.

18. Grid Code (only in Croatian), http://www.hep.hr/ops/dokument/akti/mreznaPravila.pdf

19. Ochoa, L. F., Ciric, R. M., Padilha-Feltrin, A., Harrison, G. P., 15th Power Systems Computation Conference (PSCC'05); Liege, France, pp 1-4, 22-26 Aug 2005. 